\title{
Speed-Flow Relationship at Basic Segment of Federal Highway
}

\author{
Mohd Erwan Sanik ${ }^{1,2,}$, Joewono Prasetijo ${ }^{2,3}$, and Ahmad Sofian Azmi ${ }^{3}$ \\ ${ }^{1}$ Department of Civil Engineering, Centre for Diploma Studies, Universiti Tun Hussein Onn \\ Malaysia, 86400 Parit Raja, Johor, Malaysia \\ ${ }^{2}$ Smart Driving Research Centre, Universiti Tun Hussein Onn Malaysia, 86400 Parit Raja, Johor, \\ Malaysia \\ ${ }^{3}$ Department of Infrastructure and Geomatic Engineering, Faculty of Civil and Environmental \\ Engineering, Universiti Tun Hussein Onn Malaysia, 86400 Parit Raja, Johor, Malaysia
}

\begin{abstract}
Theoretically, at many traffic facility during peak hour, speedflow relationship is only appeared as a normal flow, represented by half of speed-flow curve. Forced flow will only occur during severe overcrowding resulted in drivers trying to use all the space in a way so that the amount of overcapacity. The purpose of this study is to analyse the relationship between speed-flow traffic flows along a basic segment. The objectives of this study is to analyse the time series of speed and flow at basic segment of A550 and A551 study location for 24 hours in a month as well as to determine the maximum flow and critical speed through the speed-flow models. Data obtained from this study were analysed using video recording and image processing techniques. In order to achieve these objectives, the Federal Highway 2 was selected as location for the study. Results show that the speed - flow diagram in one month on both A550 and A551 obtain the maximum flows and critical speeds of 4200 and $5320 \mathrm{veh} / \mathrm{hr} / \mathrm{ln}$ and 55 and $60 \mathrm{~km} / \mathrm{hr}$, respectively.
\end{abstract}

\section{Introduction}

Congestion usually relates to an excess of vehicles on a portion of roadway at a particular time resulting in speeds that are slower sometimes or much slower than normal or free flow speeds [1]. When the capacity of a highway section is exceeded, breakdown occurs where speeds dropped and vehicles crowded together.

Massive daily traffic congestion along the Federal Highway 2 is common especially early in the morning and late afternoon. This congestion create a condition of forced flow which can be interpreted using the speed-flow relationship [2]. The objectives of this study is to analyse the time series of speed and flow at basic segment of A550 and A551 study location for 24 hours in a month as well as to determine the maximum flow and critical speed through the speed-flow models.

*Corresponding author: erwans@uthm.edu.my 


\section{Methodology}

\subsection{Study framework}

Fig. 1 shows the flowchart of study as framework of this study.

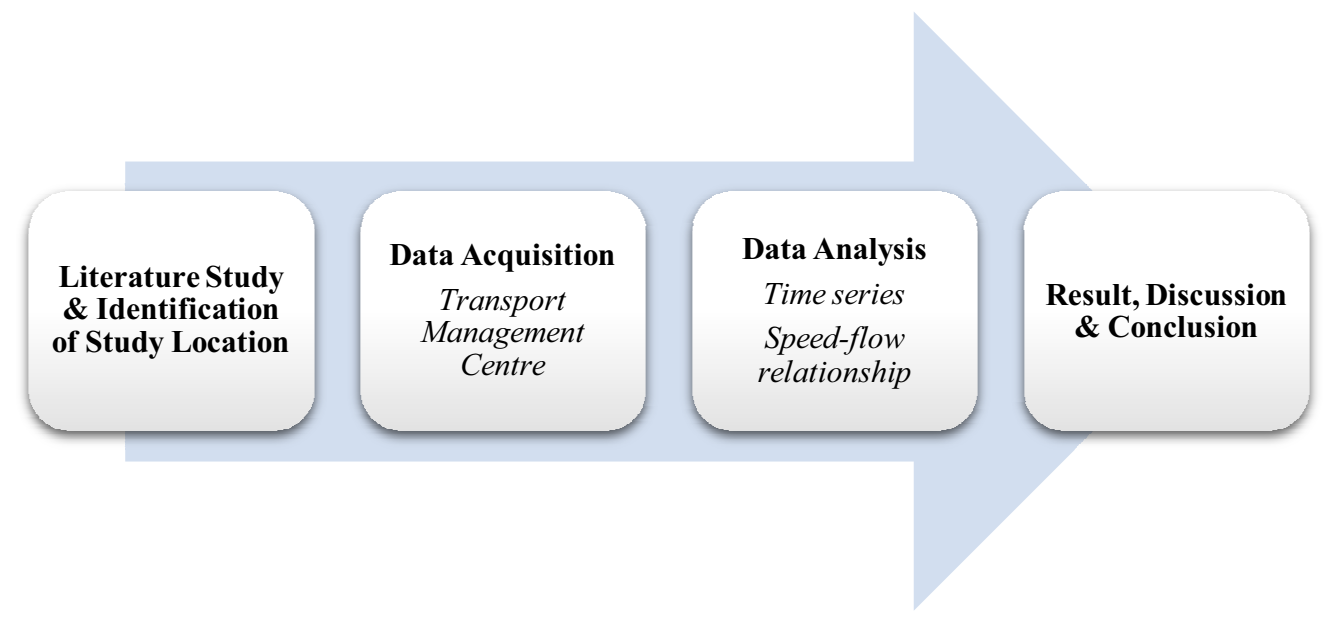

Fig. 1. Framework of study

\subsubsection{Study location and data acquisition}

This study was carried out at basic segment of Federal Highway 2 near Kompleks Astana. Secondary data were used in this study. Data were obtained from the Transport Management Centre (TMC). Two automatic incident devices were used to record and extract data at study locations, namely A550 and A551.

\subsubsection{Data analysis}

Data were plotted into time-series graph for both location. The speed and flow data were analysed to develop speed-flow relationship of both locations. The maximum flow and critical speed can be determined from the graph.

\section{Result and discussion}

All data for speed and flow rate in month of January 2012 was plotted as graph in timeseries over the period of time for each location. The primary and secondary $x$-axis on the left was represented by speed while on the right was flow rate value, respectively.

\subsection{Time series analysis}

Fig. 2 and Fig. 3 show examples of time series of speed and flow on January $1^{\text {st }}$ at A550 and A551. 


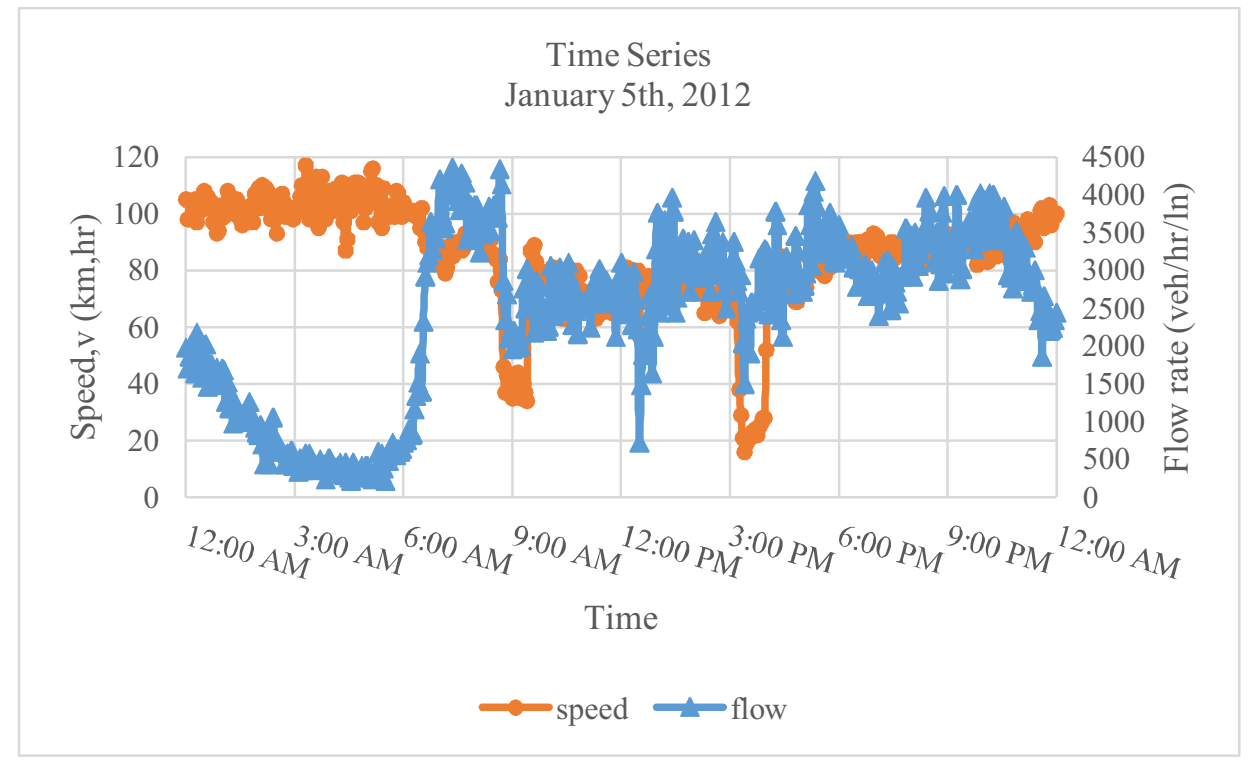

Fig. 2. Time series of speed and flow on January $1^{\text {st }} 2012$ at A550

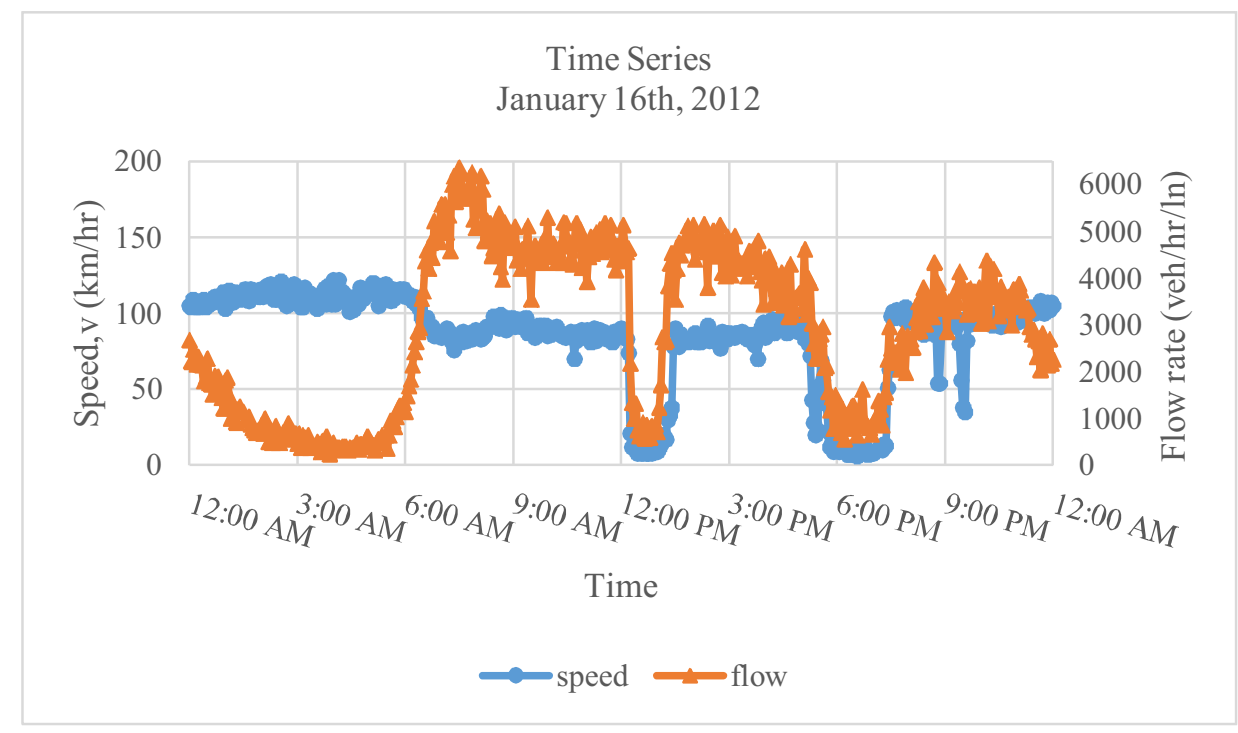

Fig. 3. Time series of speed and flow on January $1^{\text {st }} 2012$ at A551

Referring to Fig. 2, flow rate of A550 was started low at 40 to $60 \mathrm{veh} / \mathrm{hr}$ at $12.00 \mathrm{AM}$ and kept on decreasing before suddenly increasing at $5.00 \mathrm{AM}$ up to $4500 \mathrm{veh} / \mathrm{hr}$. The flow rate was then kept on highly fluctuating until 9.00 AM. However, at this morning rush hour, the speed of vehicles was start to reduce suddenly at 9.00 AM. This may due to long stretch of basic segment. The speed of vehicles was again reduce tremendously after 3.00 PM. This may due to industrial employees finish and change shift around this time and start to travel home. 
Referring to Fig. 3, several rush hours can be noticed however speeds were inaccurately reflected to the flow rate pattern. This condition may due to unexpected event on study locations that was not recorded by TMC.

\subsection{Speed-flow model}

Fig. 4 and Fig. 5 show the speed-flow relationship of AID 550 and AID 551 throughout the entire month of January 2012, respectively.

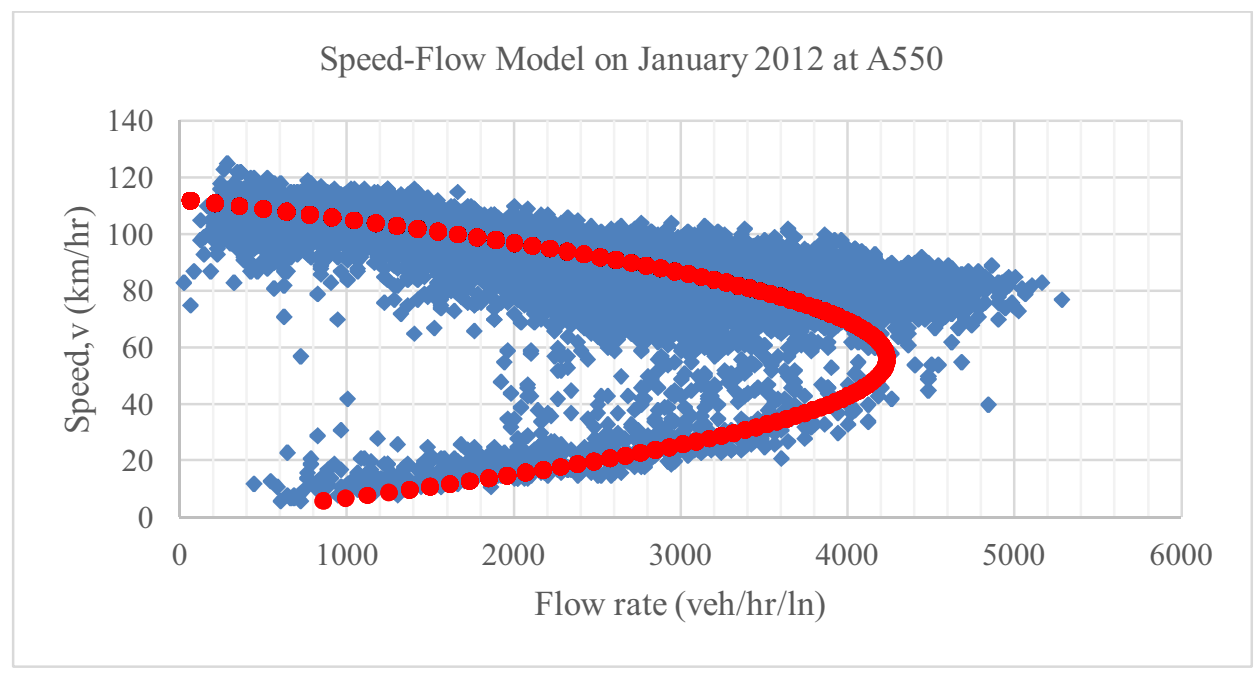

Fig. 4. Speed-flow relationship of AID 550 throughout the entire month of January 2012

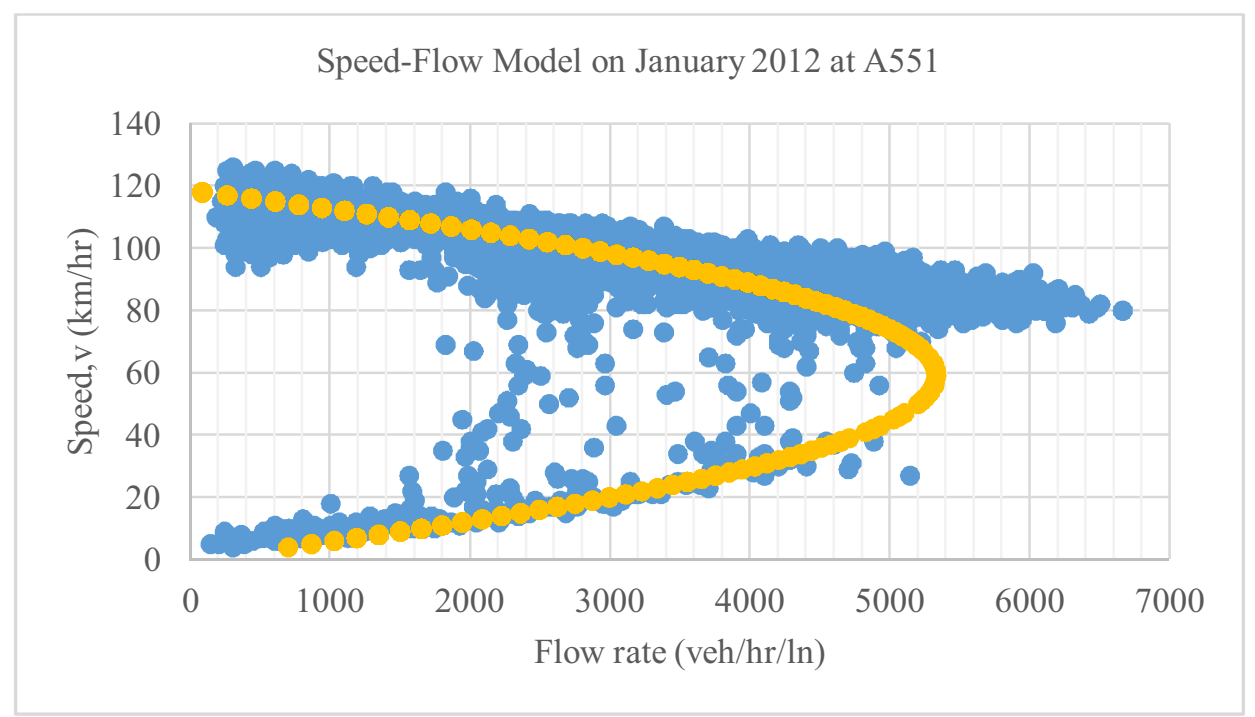

Fig. 5. Speed-flow relationship of AID 551 throughout the entire month of January 2012 
Referring to Fig. 4 and Fig. 5, the estimated maximum flow for AID 550 location is $4200 \mathrm{veh} / \mathrm{km} / \mathrm{ln}$ and the critical speed is $55 \mathrm{~km} / \mathrm{hr}$ while for AID 551 location, the maximum flow is $5320 \mathrm{veh} / \mathrm{hr} / \mathrm{ln}$ and the critical speed is $60 \mathrm{~km} / \mathrm{hr}$. The average curves to estimate maximum flow were developed using Greenshields approach [3].

\section{Conclusion}

The objectives of the study were successfully achieved and can be concluded that theoretically, during off-peak hour, the speed-flow relationship will only appear as a normal flow, represented by half of speed-flow curve. The forced flow will only happen during heavy congested while driver try to utilize all space on road until the volume exceeded capacity. At basic segment, normal flow may likely occur at all time unless in the presence of traffic accident occurrence or maintenance works at one of the lanes. By looking at the speed - flow diagram in one month on both AID 550 and AID 551 the maximum flows obtained were 4200 and $5320 \mathrm{veh} / \mathrm{hr} / \mathrm{ln}$ and 55 and $60 \mathrm{~km} / \mathrm{hr}$, respectively. The estimated maximum flow values are considerably high if compare to standard capacity of highway which is $2400 \mathrm{veh} / \mathrm{hr} / \mathrm{ln}$.

\section{References}

[1] T.V. Mathew, Freeway Operations, Transportation Systems Engineering, IIT Bombay, (2014)

[2] M. Lorenz, L. Elefteriadou, A Probabilistic Approach to Defining Freeway Capacity and Breakdown, The Pennsylvania Transportation Institute, (2000)

[3] B.D. Greenshields, A Study of Traffic Capacity, Highway Research Board, (1935) 